\title{
The 2nd EfCCNa Congress: impressions of a Polish delegate
}

Mariola Zadroga RN, ICU, Provincial Hospital, Poznañ, and Assistant Lecturer, Department of Anaesthesiology and Intensive Care Nursing, University of Medical Sciences, Poznañ, Poland.

E-mail: marzadr@op.pl

In November 10th - 12th 2005 myself and two other Polish nurses from Department of Anesthesiology and Intensive Care Nursing, University of Medical Sciences in Pozna, participated in the 2nd Congress of the EfCCNa, which took place in Amsterdam. The congress was organized with the participation of the Dutch Critical Care Nursing Association. It was the first time I took part in such a meeting and I think that it was an excellent experience to find out what is going on in critical care nursing in other European countries

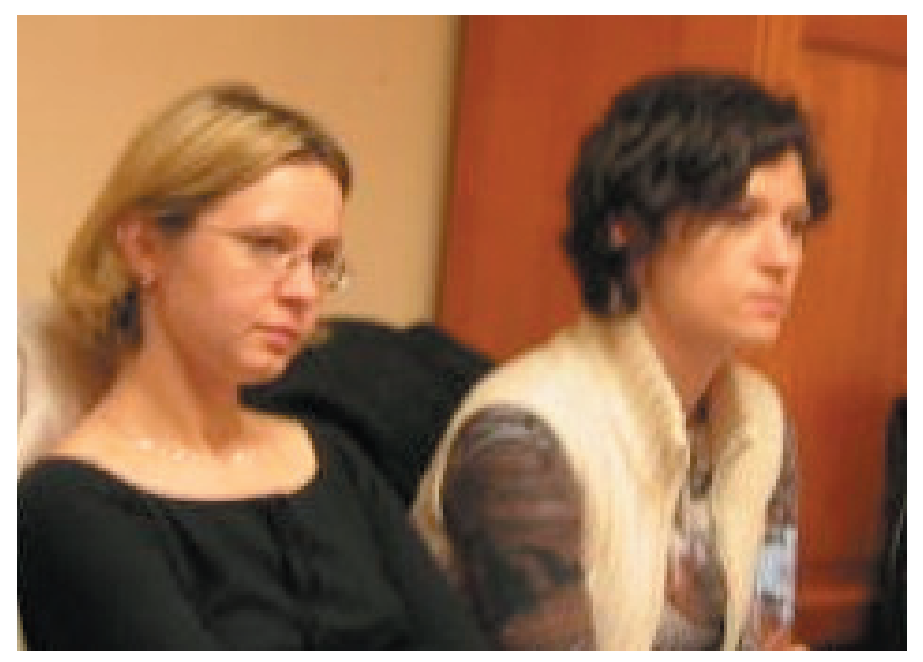

Mariola Zadroga (left) with her colleague Edyta Cudak-Bañska

The conference attracted over 400 participants, nearly twice as many as the first EfCCNa congress in 2002. It suggested to me that European nurses caring for critically ill patients want to share their knowledge and professional experience and to learn from each other as well. The conference was full of very interesting papers and the sessions were devoted to many aspects referring to nursing in ICU, e.g. workforce, practice development, technology, ventila- tion, pain and sedation, nutrition, management as well as education, research and ethics. Specific issues relating to paediatric critical care were also included in the busy programme, so everyone had the opportunity to find something interesting that would meet their specific needs. The scientific committee succeeded in making the congress attractive and inspiring.

Each of the sessions I attended generated discussion and sharing of professional opinions giving participants the chance to hear something new. My colleagues and I participated in as many sessions as possible in order to profit from the conference programme. I appreciated particularly Professor Julie Scholes' presentations. She talked about critical care competencies among other things and she illustrated her papers with many pictures that were accompanied by well chosen music. Her keynote was highly informative and moving. The congress thus provided us with knowledge as well as positive emotions.

During the breaks the participants had the opportunity to see nearly 40 posters which supplemented the oral presentations. Our Polish contribution to the congress included: the paper "To what extent are holistic indices realized in intensive care units?", which was presented by Edyta Cudak-Bañska, Joanna Wiśniewska, and Danuta Dyk and the poster "Is postoperative pain still a problem in nursing" prepared by myself and Danuta Dyk. Our association PTPAilO was also introduced in the form of poster.

Overall, I feel that the congress was an excellent opportunity for critical care nurses to widen and update their knowledge. This is necessary if nurses want to develop the quality of nursing work. Technology and guidelines are changing and nurses have to be upto-date to be able to respond to the challenges of caring for patients along the life-continuum. Finally, the conference also gave us the chance to spend some time in the beautiful city of Amsterdam and we were impressed by its charm and atmosphere.

The 3rd EfCCNa congress is going to take place in 2008 in Italy, we are sure that it will be as fruitful as this meeting has been. The more often we meet and share ideas, the better this is for critical care nursing and patient care, see you in Italy in 2008.

Best regards from Poland. 